\title{
Comparison of clinical and economic outcomes between the direct anterior approach and the posterolateral approach for primary total hip arthroplasty
}

\author{
Paweł Skowronek ${ }^{1,2}$, Michał Dębiński ${ }^{1}$, Agnieszka Maksymiuk-Kłos ${ }^{3}$, Andrzej Zalewski ${ }^{1}$, \\ Robert Jopowicz ${ }^{1}$, Tomasz Sasinowski ${ }^{1}$, Arkadiusz Madej ${ }^{1,2}$
}

\author{
${ }^{1}$ Orthopaedic and Rehabilitation Center, Warsaw Medical University, Mazowiecki \\ Brodnowski Hospital, Warsaw, Poland \\ ${ }^{2}$ Orthopaedic and Traumatology Clinic, Regional Hospital Kielce, Jan Kochanowski \\ University, Kielce, Poland \\ ${ }^{3}$ Medical Center Enel-Med, Warsaw, Poland
}

Submitted: 18 November 2019

Accepted: 28 March 2020

Arch Med Sci

DOI: https://doi.org/10.5114/aoms.2020.97277

Copyright $\odot 2020$ Termedia \& Banach

\begin{abstract}
Introduction: Total hip arthroplasty (THA) is one of the most frequently performed surgical procedures in orthopedics. The most commonly employed approaches are the posterolateral approach (PLA) and the lateral approach. Minimally invasive techniques such as direct anterior approach (DAA) and MIS DAA (minimal invasive surgery direct anterior approach) are used more and more often. The aim of the study was to compare the two approaches DAA and PLA in terms of length of stay, economic outcomes, quality of life, hip joint function and hip joint awareness.

Material and methods: The study was performed as a retrospective analysis of 52 cementless total hip arthroplasty procedures performed by MIS DAA and 56 cementless THA performed by classic standard PLA. The evaluation of hip joint awareness, quality of life, hip joint fitness assessment and economic indicators were evaluated.

Results: The mean duration of the anterior approach procedure (48.96 minutes) was found to be around half that of the posterior approach (102.52 minutes) (Levene's test: $F=2.37 ; p>0.005$ ). The mean durations of the two types of approaches were found to be significantly different (Student's $t$ test: $t(106)=-16.15 ; p<0.005)$. The shorter mean duration of stay and shorter procedure duration associated with the anterior approach result in mean savings of PLN 5465.96 per procedure.

Conclusions: The MIS DAA procedure is a safe and less traumatizing surgical approach for hip arthroplasty which allows faster post-operative primary mobilization, shorter procedure time and sooner discharge from hospital than standard PLA. Significant reduction in costs of hospitalization was observed in the MIS DAA procedure.
\end{abstract}

Key words: direct anterior approach, posterolateral approach, clinical and economic outcomes, primary total hip arthroplasty.
Corresponding author: Agnieszka Maksymiuk-Kłos MD Medical Center Enel-Med Warsaw, Poland

E-mail: agamaksymiuk@gmail.com 


\section{Introduction}

Total hip arthroplasty (THA) is one of the most frequently performed surgical procedures in orthopedics $[1,2]$. Recently, with a continual lengthening of the mean lifespan an increase has been noted in the number of patients with degenerative disease. This increase has been accompanied by greater numbers of endoprosthesis procedures. Over 200000 THA procedures were performed in the USA in 2005 , and this number is predicted to rise to over 570000 by 2030 [3]. The projected increase in annual THA performed in the US for 2040 is $284 \%$ compared to 2014 data [3]. Similarly, costs associated with THA in the USA, currently estimated at over $\$ 13.7$ billion in 2009, are expected to rise by $175 \%$ by the year $2030[4,5]$.

Although a range of THA techniques can be performed, the most commonly employed approaches are the posterolateral approach (PLA) and lateral approach $[6,7]$. However, the last twenty years have seen a growth in interest in the use of minimally invasive techniques. One form of minimally invasive procedure employs the direct anterior approach (DAA, MIS DAA).

It has been proposed that MIS DAA may be associated with minimal tissue damage, a shorter surgery procedure, less exposure of the wound, reduced use of analgesic substances, post-operative pain killers and better function of the operated joint compared to PLA [7-13]. In addition, MIS DAA demonstrates a very low frequency of complications [14-17]. Previous works suggest that DAA offers shorter hospitalization time, i.e. length of stay (LOS), than PLA $[15,16,18-20]$.

LOS is thought to have the greatest influence on inter alia the number of postoperative complications, the risk of hospital infection, the overall cost of therapy and the ultimate postoperative outcome [15, 17, 21-30].

The choice of surgical approach, which potentially allows faster and more effective patient mobilization and rehabilitation, and thus a shorter hospitalization time, can bring a number of benefits for both the patient and the treatment center.

The aim of the study was to compare two approaches, DAA and PLA, in terms of LOS, economic outcomes, quality of life, hip joint function and hip joint awareness.

\section{Material and methods}

The study was performed as a retrospective analysis of 52 cementless total hip arthroplasty procedures performed by MIS DAA and 56 cementless THA performed by classic standard PLA (the characteristics of the groups are presented in Tables I and II) in the period 2017-2018 in orthopedic centers in two cities in Poland.
The exclusion criteria comprised:

- post-traumatic arthrosis,

- post-infectious arthrosis,

- hip joints which had been operated on previously,

- hip joint dysplasia - Crowe type $>\mathrm{II}$,

- ASA (American Society of Anesthesiologists Scale) score below 2.

All patients qualified for the study, i.e. both the DAA and PLA groups, were operated on under spinal anesthesia.

Patients qualified for surgery were admitted to the hospital 24 hours before the planned procedure. The LOS was calculated from the time of admission to the time of discharge. All the procedures took place within the planned time, i.e. within 24 hours following admission to the hospital. All patients qualified for THA received a diagnostic survey using the HHS (Harris Hip Score), FJS-12 (Forgotten Joint Score 12) and WHOQOL (World Health Organization Quality of Life scale). This procedure was repeated after three months, and again after six months. In addition, the level of pain in the operated joint was assessed each day during hospitalization on the VAS (Visual Analog Scale).

The PLA and DAA procedures were performed in the period 2017-2018 by a two single surgeons who perform a minimum of 80 PLA and 80 DAA hip replacement operations each year. They had at least eight years' experience of performing THA surgery.

The PLA procedure was performed according to the standard method. MIS DAA was performed through the intramuscular space between the tensor fasciae late muscle and the sartorius muscle $[11,19,31,32]$. No incisions were performed with the aim of dissecting the muscles. During the preparation of the proximal part of the femur, the operating table was hyperextended at 15 degrees to the hip. The standard '4' position was replaced by a 20-degree bend in the knee joint and an external rotation of 90 degrees. This method allowed the tissue trauma to be minimized without worsening the operating conditions and femur exposure during implantation of the hip stem. After completion of only the fascia, subcutaneous tissue and skin were sutured. This method allowed the tissue trauma to be minimized without worsening the operating conditions and femur exposure during implantation of the hip stem.

At the beginning of the procedure, each patient received $1 \mathrm{~g}$ of intravenous tranexamic acid [31]. No automatic retractors, traction tables or fluoroscopy were used during the procedures. No drain was used in the PLA and MIS DAA groups. Compression dressings and drainage were not used. Implants available in the clinics which took part in the study were used for the procedure.

Both groups had postoperative X-rays of the hip joints within 24 hours of the end of the procedure, 
Table I. Descriptive statistics of continuous biodemographic variables - summary

\begin{tabular}{|c|c|c|c|c|c|c|c|}
\hline Parameter & $N$ & $\mathrm{R}$ & $M$ & SD & Sk & Kurt & W \\
\hline \multicolumn{8}{|l|}{ Total } \\
\hline Age & 108 & $43-93$ & 66.38 & 8.74 & -0.07 & 0.67 & $0.10^{*}$ \\
\hline Body weight & 108 & $45-134$ & 83.12 & 16.43 & 0.22 & 0.18 & 0.07 \\
\hline Height & 108 & $145-194$ & 167.63 & 9.57 & 0.22 & -0.10 & $0.10^{*}$ \\
\hline $\mathrm{BMI}$ & 108 & $18.03-46.67$ & 29.50 & 4.97 & 0.51 & 0.73 & 0.07 \\
\hline Procedure duration & 108 & $30-165$ & 76.73 & 31.88 & 0.33 & -0.84 & $0.17^{\star *}$ \\
\hline LOS & 108 & $3-19$ & 6.32 & 2.56 & 1.62 & 4.71 & $0.15^{\star *}$ \\
\hline \multicolumn{8}{|l|}{ PLA } \\
\hline Age & 56 & $44-86$ & 66.80 & 9.12 & -0.09 & -0.00 & 0.99 \\
\hline Body weight & 56 & $45-120$ & 83.57 & 16.00 & 0.03 & -0.00 & 0.98 \\
\hline Height & 56 & $149-184$ & 168.54 & 7.80 & -0.41 & -0.12 & 0.97 \\
\hline BMI & 56 & $18.03-39.90$ & 29.33 & 4.87 & 0.35 & 0.18 & 0.97 \\
\hline Procedure duration & 56 & $70-165$ & 102.52 & 18.43 & 1.16 & 1.82 & $0.91^{\star *}$ \\
\hline LOS & 56 & $6-19$ & 8.14 & 2.30 & 2.27 & 8.07 & $0.78^{* *}$ \\
\hline \multicolumn{8}{|l|}{ DAA } \\
\hline Age & 52 & $43-93$ & 65.92 & 8.38 & -0.07 & 1.86 & $0.95^{\star}$ \\
\hline Body weight & 52 & $50-134$ & 82.63 & 17.02 & 0.40 & 0.48 & 0.98 \\
\hline Height & 52 & $145-194$ & 166.65 & 11.17 & 0.58 & -0.18 & $0.95^{\star}$ \\
\hline BMI & 52 & $19.33-46.67$ & 29.68 & 5.11 & 0.66 & 1.34 & 0.97 \\
\hline Procedure duration & 52 & $30-120$ & 48.96 & 15.80 & 2.60 & 8.68 & $0.73^{* *}$ \\
\hline LOS & 52 & $3-6$ & 4.37 & 0.71 & 0.33 & 0.07 & $0.83^{* *}$ \\
\hline \multicolumn{8}{|l|}{ Women } \\
\hline Age & 56 & $48-86$ & 67.41 & 8.21 & -0.16 & 0.22 & 0.97 \\
\hline Body weight & 56 & $45-110$ & 75.55 & 14.45 & 0.15 & -0.05 & 0.99 \\
\hline Height & 56 & $145-173$ & 160.80 & 5.70 & -0.60 & 0.41 & 0.96 \\
\hline BMI & 56 & $18.03-46.67$ & 29.21 & 5.44 & 0.50 & 0.91 & 0.98 \\
\hline Procedure duration & 56 & $30-140$ & 71.36 & 31.38 & 0.39 & -1.27 & $0.89^{* *}$ \\
\hline LOS & 56 & $3-19$ & 5.98 & 2.69 & 2.42 & 8.98 & $0.77^{* *}$ \\
\hline \multicolumn{8}{|l|}{ Men } \\
\hline Age & 52 & $43-93$ & 65.27 & 9.23 & 0.08 & 1.17 & 0.98 \\
\hline Body weight & 52 & $62-134$ & 91.27 & 14.51 & 0.48 & 0.34 & 0.98 \\
\hline Height & 52 & $155-194$ & 174.98 & 7.14 & 0.14 & 1.04 & 0.97 \\
\hline BMI & 52 & $20.96-40.45$ & 29.81 & 4.44 & 0.63 & 0.19 & $0.95^{*}$ \\
\hline Procedure duration & 52 & $35-165$ & 82.52 & 31.69 & 0.30 & -0.41 & $0.94^{*}$ \\
\hline LOS & 52 & $3-13$ & 6.69 & 2.38 & 0.65 & 0.02 & $0.94^{\star}$ \\
\hline
\end{tabular}

$B M I$ - body mass index, LOS - length of stay, PLA - posterolateral approach, DAA - direct anterior approach (DAA).

received prophylactic antibiotic therapy (cefazolin), prophylaxis during hospitalization and analgesic low molecular weight heparins as antithrombotic treatment in accordance with the analgesic ladder. 
Table II. Percentage distributions of qualitative demographic variables

\begin{tabular}{|lcc|}
\hline Parameter & $n$ & $\%$ \\
\hline \begin{tabular}{l} 
Group \\
\hline Posterolateral approach
\end{tabular} & 56 & 51.9 \\
\hline Direct anterior approach & 52 & 48.1 \\
\hline Side & & \\
\hline Right & 47 & 43.5 \\
\hline Gender & 61 & 56.5 \\
\hline Women & & \\
\hline Men & 56 & 51.9 \\
\hline Inhabitancy & 52 & 48.1 \\
\hline Village & & \\
\hline City & 52 & 48.1 \\
\hline Education & 56 & 51.9 \\
\hline Primary & 15 & 14.2 \\
\hline Vocational & 32 & 29.2 \\
\hline Secondary & 42 & 39.6 \\
\hline Higher & & \\
\hline
\end{tabular}

Other internal medicine was administered according to the individual needs of the patient.

On the first day after the procedure, all patients were mobilized with the assistance of a physiotherapist and began learning to walk using crutches or a walking frame. Postoperative rehabilitation followed the same pattern in both examined groups. The patients were discharged from the department on the day they met the discharge criteria:

- independent movement using one or two crutches or a walking frame,

- independent movement on the stairs,

- sufficient functional range of motion in the operated joint $\left(0-90^{\circ}\right)$

- understanding further discharge recommendations,

- hemoglobin level above $9 \mathrm{mg} / \mathrm{dl}$,

- VAS score below 3.

Postoperative follow-up visits were carried out by operators after three and six months after the operation. Data regarding the cost of MIS DAA were obtained from the hospital which performed the procedure.

\section{Statistical analysis}

All statistical analyses were performed using Statistica 9.0 software. The Kolmogorov $\lambda$-test was used to determine whether the results were normally distributed. As the distribution was normal, Student's $t$-test for independent events was then used to compare the length of stay for each patient following the operation.

Descriptive statistics were calculated for the following indicators: hip function according to the HHS questionnaire, the level of joint awareness measured by the FJS-12 questionnaire and the quality of life measured by the WHOQOL-Brief questionnaire.

Each parameter was measured three times for each patient, i.e. before the operation (P1), three months after the operation (P2) and six months after the operation (P3), giving three measurements per value (Stanisz, 2007). As the measurements were all quantitative, the entire spectrum of descriptive statistics was applied: range (min-max), measures of central tendency (mean) and distribution (standard deviation), and measures of location (skewness, kurtosis).

\section{Results}

To determine the homogeneity of the groups identified in the study, they were compared in terms of demographic variables. All were found to be homogeneous according to age, body mass index (BMI), sex distribution, and ASA qualification by an anesthesiologist.

Neither group demonstrated any significant postoperative complications that would affect the time of hospitalization, such as DVT/PE, dislocation or loosening of the endoprosthesis components, or early signs of infection. All patients demonstrated a hemoglobin level above $9 \mathrm{mg} / \mathrm{dl}$; none of the patients required blood transfusion.

The length of stay in the hospital, and the duration of the procedure according to operative approach, are included in Table III.

The two approach types did not display homogeneity of variance with regard to the mean duration of the procedure (Levene's test: $F=17.89$; $p<0.005)$. The choice of approach significantly influenced the mean LOS (Student's $t$-test: $t(66)=-11.70$;

Table III. The mean length of hospitalization values were compared between approach types (DAA and PLA)

\begin{tabular}{|lccccc|}
\hline Parameter & $n$ & Minimum & Maximum & Mean & Standard deviation \\
\hline Procedure duration [days] & 108 & 30 & 165 & 76.73 & 31.882 \\
\hline Length of hospitalization [days] & 108 & 3 & 19 & 6.32 & 2.561 \\
\hline
\end{tabular}


$p<0.005)$ : it was found to be significantly shorter for the anterior approach (DAA) (4.37 days) than the posterior approach (8.14 days) (Student's $t$-test for independent variables: $p<0.005)$

The mean duration of the anterior approach procedure (48.96 minutes) was found to be around half that of the posterior approach (102.52 minutes). Variations in mean duration within the groups were found to be homogeneous (Levene's test: $F=2.37 ; p>0.005)$. The mean durations of the two types of approaches were found to be significantly different (Student's $t$ test: $t(106)=-16.15 ; p<0.005)$.

A VAS score level below 3 was acquired in the DAA group at 1.47 days post-operatively and 1.94 days in the PLA group. The difference showed statistical significance.

The financial costs of the stay in the ward were analyzed. It was assumed that the fixed costs (food, nursing, energy, cost of hospital administration) only constituted a small share of the total cost of stay. In addition, as both types of approaches had similar fixed costs, it is reasonable to omit these charges in further calculations. The cost of the procedure was found to be the same in both hospitals: the mean cost of the stay was PLN 377, and the costs resulting from the operation were PLN 4531/hour of work in the operation room. Hence, it can be concluded that the shorter mean duration of stay and shorter procedure duration associated with the anterior approach result in mean savings of PLN 5465.96 per procedure.

\section{Hip joint fitness assessment}

Identical hip function measured as the Harris Hip Score was found in the individual anterior and posterior groups, and in both groups combined. In each case, all three consecutive measurements, i.e. postoperative, after three months and after six months, significantly differed from each other (each < 0.001): Improved hip function was observed immediately after the operation, and this improvement was even greater after six months.

The measurements taken immediately after the operation demonstrated a significant difference with regard to interaction effect $(p=0.019)$. Both groups reported equally low performance before the operation and higher performance six months later; however, 3 months after the operation, the anterior group reported significantly worse performance (approximately 7\%) than the posterolateral group.

\section{Evaluation of quality of life}

The patients reported higher quality of life measured according to the WHOQOL-BREF following the operation. Statistical analysis confirmed that the quality of life had significantly improved immediately after the operation, and continued to improve over the following six months (all $p<0.001$ ). No significant difference was observed between the two approaches.

\section{Evaluation of hip joint awareness}

Significant differences were observed between successive measurements of the hip joint measured on the FJS12 scale - hip joint feeling was approximately $25 \%$ higher before the operation than afterwards; this value had fallen by $17 \%$ after the following six months ( $p<0.001)$. In addition, patients treated by the posterior approach were significantly more likely to experience higher hip joint awareness than those treated by the anterior approach $(p<0.001)$.

All data discussed above are presented in Tables III-VIII.

\section{Discussion}

The growing demand for THA should motivate clinicians to improve the course of treatment and rehabilitation while maintaining an appropriate level of safety for the patient [3-5]. The LOS of a patient following THA has a significant influence on the final outcome of treatment [25], and there is a great interest in reducing the LOS for both medical and economic reasons [24].

Our findings demonstrate that the DAA enables a significant shortening of the LOS while also maintaining patient safety and ensuring adequate rehabilitation. Better VAS scores, indicating less pain, were obtained for the DAA group during the first few days after the operation. Similarly, Wang reported both better VAS scores immediately after the operation and better Harris hip score results in the second and fourth week following the procedure. No other differences were found between the DAA and PLA groups [33]. The use

Table IV. Length of hospitalizations

\begin{tabular}{|lccc|}
\hline Approach & Mean & $n$ & Standard deviation \\
\hline Anterior [days] & 4.37 & 52 & 0.715 \\
\hline Posterior [days] & 8.14 & 56 & 2.300 \\
\hline Overall & 6.32 & 108 & 2.561 \\
\hline
\end{tabular}

Table V. Procedure duration

\begin{tabular}{|lccc|}
\hline Approach & Mean & $n$ & Standard deviation \\
\hline Anterior [min] & 48.96 & 52 & 15.805 \\
\hline Posterior [min] & 102.52 & 56 & 18.432 \\
\hline Overall & 76.73 & 108 & 31.882 \\
\hline
\end{tabular}


Table VI. Consecutive measurements of the functional capability of the hips of patients undergoing posterior approach surgery and interaction of these two factors: descriptive statistics, effect size and post-hoc tests

\begin{tabular}{|c|c|c|c|c|c|c|c|}
\hline & & $M$ & SD & $F$ & $p$ & $\eta 2$ & Post-hoc \\
\hline A & Before operation & 45.54 & 15.94 & 494.65 & 0.000 & 819 & $A<B^{* *}$ \\
\hline B & After 3 months & 81.21 & 11.51 & & & & $A<C^{* *}$ \\
\hline C & After 6 months & 89.53 & 13.48 & & & & $B<C^{* *}$ \\
\hline I & Posterior approach & 72.22 & 25.95 & 0.05 & 826 & 0.000 & n.i. \\
\hline II & Anterior approach & 72.01 & 20.63 & & & & \\
\hline I.A & Posterior before operation & 43.32 & 16.00 & 5.23 & 9 & 0.009 & $|\mathrm{~B}>\|| \mathrm{B} \mathrm{B}^{*}$ \\
\hline I.B & Posterior after 3 months & 83.76 & 13.29 & & & & I. $A<I . B^{* *}$ \\
\hline I.C & Posterior after 6 months & 89.91 & 17.52 & & & & I.A<I. $C^{* *}$ \\
\hline II.A & Anterior before operation & 47.98 & 15.67 & & & & I. B $<I . C^{* *}$ \\
\hline II.B & Anterior after 3 months & 78.46 & 8.53 & & & & $\|. A<\| . B^{\star \star}$ \\
\hline II.C & Anterior after 6 months & 89.13 & 7.22 & & & & $\|. A<\| . C^{* *}$ \\
\hline & & & & & & & $\|. B<\| . C^{* \star}$ \\
\hline
\end{tabular}

Table VII. Quality of life of patients undergoing surgery by the anterior and posterior approaches and the interaction between two factors: descriptive statistics, effect size and post-hoc tests

\begin{tabular}{|c|c|c|c|c|c|c|c|}
\hline & & $M$ & SD & $F$ & $p$ & $\eta 2$ & Post-hoc \\
\hline A & Before operation & 65.90 & 9.67 & 89.69 & 0.000 & 0.446 & $A<B$ \\
\hline B & After 3 months & 71.94 & 9.85 & & & & $A<C$ \\
\hline C & After 6 months & 73.66 & 9.84 & & & & $B<C$ \\
\hline I & Posterior approach & 71.03 & 11.05 & 0.56 & 0.456 & 0.005 & n.i. \\
\hline II & Anterior approach & 69.94 & 9.44 & & & & \\
\hline I.A & Posterior before operation & 65.25 & 9.98 & 7.24 & 0.002 & 0.036 & I.A $A$ I.B \\
\hline I.B & Posterior after 3 months & 73.09 & 10.62 & & & & I.A $A$ I.C \\
\hline I.C & Posterior after 6 months & 74.83 & 10.28 & & & & I.B $<$ I.C \\
\hline II.A & Anterior before operation & 66.62 & 9.36 & & & & II.A<II.B \\
\hline II.B & Anterior after 3 months & 70.72 & 8.89 & & & & II.A<II.C \\
\hline II.C & Anterior after 6 months & 72.43 & 9.28 & & & & $\|. B<\| . C$ \\
\hline
\end{tabular}

of the DAA is also associated with a lower chance of iatrogenic damage of muscle structures, shorter procedure, less intraoperative blood loss and less postoperative pain, resulting in faster mobilization following the operation [13-17].

As indicated by our present findings, the DAA approach is associated with not only a shorter procedure but also a significantly shorter stay in the ward. In our opinion, the significant difference in LOS observed in the present study between approaches stems from the differences in tissue trauma during the operation. The greater tissue trauma in the case of PLA results in greater pain and limitation of independent functioning during the first postoperative days, and thus lower fulfillment of the discharge criteria.

The literature provides no standardized criteria that the patient must fulfill on the day of discharge following THA: each researcher devises a specific criterion believed to be the most appropriate for a given population [34]. In Poland, the mean time to rehabilitation is 109 days; therefore, in our case, the most important criteria were the period of time before independent functioning, and a VAS score below 3 successfully treated with the help of the first and second levels of the analgesic ladder. Our criteria were based on the works of Larsen and of Lazie [26, 34]. 
Table VIII. Joint awareness at successive observations of patients undergoing surgery by the anterior and posterior approaches, and the interaction between two factors: descriptive statistics, effect size and post-hoc tests

\begin{tabular}{|c|c|c|c|c|c|c|c|}
\hline & & M & SD & $\mathrm{F}$ & $p$ & $\eta 2$ & Post-hoc \\
\hline A & Before operation & 53.21 & 7.86 & 181.68 & 0.000 & 0.604 & $A<B^{\star *}$ \\
\hline B & After 3 months & 40.36 & 12.34 & & & & $A<C^{\star *}$ \\
\hline C & After 6 months & 33.15 & 13.87 & & & & $B<C^{* *}$ \\
\hline I & Posterior approach & 46.22 & 13.74 & 27.90 & 0.000 & 0.211 & $|>|^{* *}$ \\
\hline II & Anterior approach & 37.94 & 13.60 & & & & \\
\hline I.A & Posterior before operation & 54.61 & 7.84 & 15.22 & 0.000 & 0.051 & $|. A>|\left|. A^{* \star},\right| B>|| B^{\star *}$ \\
\hline I.B & Posterior after 3 months & 43.80 & 13.88 & & & & $|. C>| I . C^{* *},|. A>| . B^{* *}$ \\
\hline I.C & Posterior after 6 months & 40.13 & 14.31 & & & & I. $A<1 . C^{\star \star}$ \\
\hline II.A & Anterior before operation & 51.67 & 7.68 & & & & I. $B<1 . C^{* *}$ \\
\hline II.B & Anterior after 3 months & 36.65 & 9.20 & & & & II. $A<\| . B^{\star *}$ \\
\hline II.C & Anterior after 6 months & 25.77 & 8.67 & & & & $\|. A<\| . C^{\star *}$ \\
\hline & & & & & & & $\|. B<\| . C^{* *}$ \\
\hline
\end{tabular}

Selected works demonstrate that shorter hospitalization after THA may yield a range of benefits for patients. A correlation was observed between shorter LOS and better long-term postoperative results, as well as with greater satisfaction with the treatment, as reported by Husted et al. and Larsen et al. [25, 26], among others. In addition, Yannick et al. note that the introduction of a 24-hour fast-track procedure after THA allows for effective postoperative rehabilitation and better education among patients, despite the LOS being significantly shortened [20].

Complications associated with longer hospitalization time are not only a medical problem but also generate additional economic problems. The economic aspect of LOS is an important one. Shorter LOS and the introduction of a fast-track procedure after THA may be associated with a reduced risk of thromboembolic events and deep periprosthetic infections [22, 27]. In the US, the annual costs associated with revision hip replacement after septic loosening increased from 320 million to 566 million dollars during the period 2001 to 2009 [28, 29]. A study in Finland found that periprosthetic infection increased treatment costs threefold compared to uncomplicated primary THA [30].

In Poland, the THA procedure is paid by the public insurance (NFZ) as a flat rate, and as the LOS in the hospital has no effect on the cost of reimbursement to hospital. The total cost of treatment is reduced by a shorter stay in hospital and by a shorter duration of the procedure [35]. In the present study, we achieved a saving of PLN 5465.96 per procedure. Shorter LOS can also have a positive impact on the efficiency of the ward and operating theatre, and shorten waiting times for surgery. A UK House of Commons report of 2003/2004 indicated that shortening LOS by one day in a 40-bed ward allows 146 additional THA treatments to be performed per year [36]. In the present study, the use of the MIS DAA approach resulted in hospitalization time being shortened by 3.8 days. The costs associated with the treatment of postoperative complications can also be lowered indirectly by reducing the risk of infection, the need for transfusion of blood products during MIS DAA, and the risk of thromboembolic events [22, 28-30, 37].

The present study does have some limitations. Patients were operated on by two different specialists. Surgeons who routinely perform THA, both in Poland and elsewhere, typically choose one preferred approach in which they train and specialize. It is important to emphasize that in this case, both surgeons had similar experience and had performed a similar numbers of procedures. In addition, due to the number of procedures performed, they were not subject to the learning curve effect.

Another limitation is that the patients from the DAA and PLA groups were treated in two different centers. However, although the rehabilitation and perioperative care protocols are standardized between the two departments, and hence any such differences should be minimized, this fact does bear consideration when interpreting the results.

Our findings, however, clearly indicate that the MIS DAA approach has a significant influence on shortening hospitalization and procedure duration, which is associated with a number of benefits for both the patient and the hospital. However, 
further randomized prospective studies are needed to more precisely evaluate this relationship.

In conclusion, the MIS DAA procedure is a safe and less traumatizing surgical approach for hip arthroplasty which allows faster primary mobilization post-operatively, shorter procedure time and sooner discharge from hospital than standard PLA; however, similar improvements in function and quality of life were observed in both groups of patients, i.e. both the DAA and PLA groups. It appears that MIS DAA is the optimal surgical approach to THA both for patients wishing to quickly return to mobility and for the operating center which intends to significantly reduce its costs of hospitalization.

\section{Conflict of interest}

The authors declare no conflict of interest.

\section{References}

1. Molina CS, Thakore RV, Blumer A, Obremskey WT, Sethi MK. Use of the National Surgical Quality Improvement Program in orthopaedic surgery. Clin Orthop Relat Res 2015; 473: 1574-81.

2. Felson DT, Zhang Y. An update on the epidemiology of knee and hip osteoarthritis with a view to prevention. Arthritis Rheum 1998; 41: 1343-55.

3. Singh JA, Yu S, Chen L, Cleveland JD. Rates of total joint replacement in the United States: future projections to 2020-2040 using the national inpatient sample.

4. National and regional estimates on hospital use for all patients from the HCUP nationwide inpatient sample (NIS). National statistics - principle procedure only. Agency for Healthcare Research and Quality. HCUPnet2011.

5. Cross M, Smith E, Hoy D, et al. The global burden of hip and knee osteoarthritis: estimates from the global burden of disease 2010 study. Ann Rheum Dis 2014; 73: 1323-30.

6. Bergin PF, Doppelt JD, Kephart CJ, et al. Comparison of minimally invasive direct anterior versus posterior total hip arthroplasty based on inflammation and muscle damage markers. J Bone Joint Surg Am 2011; 93: 1392-8.

7. Higgins BT, Barlow DR, Heagerty NE, Lin TJ. Anterior vs. posterior approach for total hip arthroplasty, a systematic review and meta-analysis. J Arthroplasty 2015; 30: 419-34.

8. Berend KR, Lombardi AV Jr, Seng BE, Adams JB. Enhanced early outcomes with the anterior supine intermuscular approach in primary total hip arthroplasty. J Bone Joint Surg Am 2009; 91 Suppl 6: 107-20.

9. Alecci V, Valente M, Crucil M, Minerva M, Pellegrino CM, Sabbadini DD. Comparison of primary total hip replacements performed with a direct anterior approach versus the standard lateral approach: perioperative findings. J Orthop Traumatol 2011; 12: 123-9.

10. Goebel S, Steinert AF, Schillinger J, et al. Reduced postoperative pain in total hip arthroplasty after minimal-invasive anterior approach. Int Orthop 2012; 36: 491-8.

11. Barrett WP, Turner SE, Leopold JP. Prospective randomized study of direct anterior vs postero-lateral approach for total hip arthroplasty. J Arthroplasty 2013; 28: 1634-8.
12. Lee SH, Kang SW, Jo S. Perioperative comparison of hip arthroplasty using the direct anterior approach with the posterolateral approach. Hip Pelvis 2017; 29: 240-6.

13. Skowronek P, Wypniewski K, Zalewski A, Sibiński M, Polguj M. Time efficiency of direct anterior hip arthroplasty compared to postero-lateral approach. Arch Med Sci [In press].

14. Wenz JF, Gurkan I, Jibodh SR. Mini-incision total hip arthroplasty: a comparative assessment of perioperative outcomes. Orthopedics 2002; 25: 1031-43.

15. Kennon RE, Keggi JM, Wetmore RS, Zatorski LE, Huo MH, Keggi KJ. Total hip arthroplasty through a minimally invasive anterior surgical approach. J Bone Joint Surg Am 2003; 85-A Suppl 4: 39-48.

16. Sariali E, Leonard P, Mamoudy P. Dislocation after total hip arthroplasty using Hueter anterior approach. J Arthroplasty 2008; 23: 266-72.

17. Post ZD, Orozco F, Diaz-Ledezma C, Hozack WJ, Ong A. Direct anterior approach for total hip arthroplasty: indications, technique, and results. J Am Acad Orthop Surg 2014; 22: 595-603.

18. Siguier T, Siguier M, Brumpt B. Mini-incision anterior approach does not increase dislocation rate: a study of 1037 total hip replacements. Clin Orthop Relat Res 2004: 164-73.

19. Matta JM, Shahrdar C, Ferguson T. Single-incision anterior approach for total hip arthroplasty on an orthopaedic table. Clin Orthop Relat Res 2005; 441: 115-24.

20. Van Den Eeden YNT, De Turck BJG, Van Den Eeden FMC. 24 hours stay after hip replacement. Acta Orthop 2017; 88: 24-8.

21. Clarke A, Rowe P, Black N. Does a shorter length of hospital stay affect the outcome and costs of hysterectomy in southern England? J Epidemiol Community Health 1996; 50: 545-50.

22. Husted H, Otte KS, Kristensen BB, Orsnes T, Wong C, Kehlet $\mathrm{H}$. Low risk of thromboembolic complications after fast-track hip and knee arthroplasty. Acta Orthop 2010; 81: 599-605.

23. Ruth Lewis NE. Improving length of stay: what can hospitals do? Nuffield Trust; 2015.

24. Scottish Arthroplasty Project Annual Report; 2018. p. 30-3.

25. Husted H, Holm G, Jacobsen S. Predictors of length of stay and patient satisfaction after hip and knee replacement surgery: fast-track experience in 712 patients. Acta Orthop 2008; 79: 168-73.

26. Larsen K, Hansen TB, Soballe K. Hip arthroplasty patients benefit from accelerated perioperative care and rehabilitation: a quasi-experimental study of 98 patients. Acta Orthop 2008; 79: 624-30.

27. Pulido L, Ghanem E, Joshi A, Purtill JJ, Parvizi J. Periprosthetic joint infection: the incidence, timing, and predisposing factors. Clin Orthop Relat Res 2008; 466: 1710-5.

28. Kurtz SM, Lau E, Watson H, Schmier JK, Parvizi J. Economic burden of periprosthetic joint infection in the United States. J Arthroplasty 2012; 27 (8 Suppl): 61-5.e1.

29. Grosse SD, Nelson RE, Nyarko KA, Richardson LC, Raskob GE. The economic burden of incident venous thromboembolism in the United States: a review of estimated attributable healthcare costs. Thromb Res 2016; 137: 3-10.

30. Puhto T, Puhto AP, Vielma M, Syrjala H. Infection triples the cost of a primary joint arthroplasty. Infect Dis (Lond) 2019; 51: 348-55.

31. Christensen CP, Karthikeyan T, Jacobs CA. Greater prevalence of wound complications requiring reoperation with direct anterior approach total hip arthroplasty. J Arthroplasty 2014; 29: 1839-41. 
32. Taunton MJ, Mason JB, Odum SM, Springer BD. Direct anterior total hip arthroplasty yields more rapid voluntary cessation of all walking aids: a prospective, randomized clinical trial. J Arthroplasty 2014; 29 (9 Suppl): 169-72.

33. Wang Z, Hou JZ, Wu CH, et al. A systematic review and meta-analysis of direct anterior approach versus posterior approach in total hip arthroplasty. J Orthop Surg Res 2018; 13: 229.

34. Lazic S, Boughton O, Kellett CF, Kader DF, Villet L, Rivière C. Day-case surgery for total hip and knee replacement: how safe and effective is it? EFORT Open Rev 2018; 3: 130-5.

35. Brunenberg DE, van Steyn MJ, Sluimer JC, Bekebrede LL, Bulstra SK, Joore MA. Joint recovery programme versus usual care: an economic evaluation of a clinical pathway for joint replacement surgery. Med Care 2005; 43: 1018-26.

36. Hip replacements: an update Seventeenth Report of Session. House of Commons Committee of Public Accounts; 2003-04.

37. Fernandez MM, Hogue S, Preblick R, Kwong WJ. Review of the cost of venous thromboembolism. Clinicoecon Outcomes Res 2015; 7: 451-62. 